\title{
A New Serological Assay of Chromogranine
}

\author{
Ritsuji YAMADA, Jin SATO, EIzo KOMIYA \\ AND TOSHIAKI NAKAI \\ Department of Clinical Pathology and Metabolism, Dokkyo \\ University School of Medicine, Mibu Town, \\ Tochigi Prefecture 321-02, Japan
}

\begin{abstract}
Synopsis
The determination of chromogranine released in exocytosis as well as of the catecholamines released from the adrenal medulla should greatly contribute not only to unraveling the mechanism of exocytosis but also to clinically diagnosing pheochromocytoma. The determination of chromogranine, however, has not been amply studied as yet.

In the first place, the catecholamine-storing vesicle-rich fraction was collected from the pig adrenal medulla by the density gradienter. In order to lyse these cell particles, they were first frozen with cold methanol, then thawed, and centrifuged. The supernatant was developed by DEAE chromatography to collect only the peak fraction, from which chromogranine was isolated. Rabbits were then injected with this chromogranine to obtain the anti-chromogranine antiserum. The successful immunization of the rabbits was demonstrated by immunodiffusion on the Ouchterlony plate.

The anti-pig chromogranine antiserum was demonstrated to be common in antigenicities with the human pheochromocytoma extract; and a serological method of chromogranine assay was then developed. For the preparation of the sensitized sheep red blood cells, the sheep red blood cells were first made to bind to the pig chromogranine by means of treating them with a formaldehyde solution and tannic acid. For the assay of the pheochromocytoma extract for chromogranine $25 \mu l$ of the extract were added to two-fold dilution series of $25 \mu l$ of the anti-chromogranine antiserum, then $25 \mu l$ of the sensitized red blood cells was added. The dilution number of the antiserum that completely inhibited hemagglutination reaction, that is, inhibition titer, was defined as the level of chromogranine. This method demonstrated the occurrence of large amounts of catecholamines in the resected tissue extract and also of chromogranine at the $1: 8$ inhibition titer.
\end{abstract}

The catecholamines, stored within the specific storage particles, chromaffin granules, of the adrenal medulla are secreted on stimulation. Based on electron microscopic studies of the chromaffin cells, the release by exocytosis was first suggested by De Robertis and Vas Ferreira (1957), and biochemical supports for this suggestion have been obtained in recent years. As no increase in the efflux of phospholipids and

Received April 18, 1977. cholesterol can be observed during the secretion of the catecholamines, the discharge of the intact chromaffin granules through the cell membrane seems unlikely (Trifaro et al., 1967).

From the isolated, perifused bovine adrenals stimulated in vitro by acetylcholine are released ATP and protein concomitantly with the catecholamines (Banks, 1966; Banks and Helle, 1965). The ratios of the catecholamines to proteins of ATP in the effluent are on the same order of magnitude 
as is found in the soluble phase of the chromaffin granules (Schneider et al., 1967; Douglas et al., 1965; Douglas and Poisner, 1966). This indicates that the granule content is released directly outside the cell.

Several methods of isolating these granules have been developed (Helle, 1966). These preparations, however, are considerably contaminated with other organelles. Of these methods, the one using Geffen's preparation has proved most excellent (Geffen et al., 1969). In the present study, chromogranine could be isolated by this method, and the successful production of an antiserum to it was achieved. As it was proved that this anti-pig chromogranine antiserum had common antigenicities with the human pheochromocytoma tissue extract, the assay system of this chromogranine was developed by a serological method.

\section{Materials and Methods}

\section{Isolation of chromogranine}

The pig adrenal glands were obtained from a local slaughter house. The glands were removed from the animals immediately after they had been slaughtered, and transported to the laboratory in an ice cooling bath. The following procedures were done in a cold room $\left(4^{\circ} \mathrm{C}\right)$. The medullas were separated from the cortices as quickly as possible, finely minced, and then homogenized in ice-cold $0.3 \mathrm{M}$ sucrose $(1: 5 \mathrm{w} / \mathrm{v})$ in a motor-driven glass homogenizer $(400 \mathrm{rpm})$.

The adrenal medullary homogenate was centrifuged at $650 \times g$ for $5 \mathrm{~min}$. The resultant pellet was discarded, and the supernatant was again centrifuged at $9,000 \times g$ for $20 \mathrm{~min}$. The pellet was resuspended in $2 \mathrm{ml}$ of $0.3 \mathrm{M}$ sucrose. The re-suspended fraction was centrifuged at $55,000 \times g$ for $90 \mathrm{~min}$ over a continuous density gradient ranging from $0.3 \mathrm{M}$ to $2 \mathrm{M}$ sucrose solution. The fractions from the density gradient were collected with a gradienter through a needle that is pierced through the top of the centrifuge tube to its bottom. Each fraction so obtained was assayed by the trihydroxyindole method for catecholamines, and the fraction rich in catecholamines was chosen as the catecholamine-storing vesicle-rich fraction. Each of these fractions were centrifugally washed twice with $0.3 \mathrm{M}$ sucrose at $9,000 \times g$. In order to lyze the cell particle, the fractions were rapidly frozen at $-20^{\circ} \mathrm{C}$ with cold methanol, thawed with running water at $15^{\circ} \mathrm{C}$, and then centrifuged at $160,000 \times g$ for $45 \mathrm{~min}$. The supernatant fractions obtained by this procedure will be called soluble lysates. Chromogranine was isolated and purified from the soluble lysates by DEAE cellulose chromatography (Geffen et al., 1969). The peak fractions separated chromatographically were collected and concentrated in vacuo with cellulose tubes (size: $8 / 32$; Visking Company).

Immunization of rabbits with chromogranine

Two rabbits were immunized by means of intramuscular injection with chromogranine $(0.5 \mathrm{ml}$ of a dialyzed sample) mixed with an equal volume of Freund's complete adjuvant (Difco Lab., Detroit, Michigan). An identical injection was given 1 month later. Blood samples were collected from the ear vein of the animals 60 days after the initial injection. The antiserum separated from the blood samples was stored at $-20^{\circ} \mathrm{C}$. Immunodiffusion on Ouchterlony plates (Munoz, 1971) was first performed as the trial method for demonstrating the successful immunization of the rabbits.

Examination of the common antigenicities between chromogranine from the pheochromocytoma and that from the pig adrenal medulla

Immunodiffusion was likewise made by Ouchterlony's method on the resected tissue extract of human pheochromocytoma, in order to study whether the chromogranine from the human adrenal medulla and that from the pig adrenal medulla are common in antigenicity or not. The extract was prepared by incubating $1 \mathrm{~g}$ of the resected tissue in $10 \mathrm{ml}$ of Ringer's solution for $30 \mathrm{~min}$.

\section{Development of a method of chromogranine assay}

The chromogranine assay system was established by a serological method, using the anti-chromogranine anti-serum obtained as described above. That is, (1) in order to prepare the sensitized blood cells, the sheep red cells were fixed in 10\% formaldehyde solution (Cox and Vermillon, 1956) and treated with a 20,000-fold dilution of tannic acid (Cambell et al., 1963) and chromogranine was allowed to bind to the cells at $37^{\circ} \mathrm{C}$ for $30 \mathrm{~min}$. In passive hemagglutination reaction, a $\mathrm{pH}-6.9$ phosphate-buffer saline solution containing $1 \%$ normal rabbit serum was used as a reaction solution diluent. (2) After the addition of $25 \mu l$ of the anti-chromogranine antiserum dilution to the sensitized blood cells, the mixture was stirred and allowed to stand at room temperature for $18 \mathrm{hr}$ to read whether hemagglutination occurs or not. The following hemagglutination inhibition reaction was allowed to proceed with an antiserum dilution which was twice as high in concentration as the maximum number of the 
antiserum dilution in which bemagglutination reaction had proved to take place. Twenty-five $\mu l$ of the effluent was collected, and prepared into two-fold dilutions. To the dilutions were added $25-\mu l$ aliquots of the anti-chromogranine antiserum dilution; the mixtures were allowed to react for $30 \mathrm{~min} ; 25 \mu \mathrm{l}$ of the corresponding sensitized red cells was added to each of the mixtures; the mixtures were thoroughly stirred, allowed to stand at room temperature for $18 \mathrm{hr}$, and hemagglutination reaction was measured in order to determine the number of dilution of the effluent in which the hemagglutination reaction was completely inhibited.

In the last place, the resected tissue extract of human pheochromocytoma was assayed for chromogranine by the use of this assay system.

\section{Results}

Chromogranine was purified from the pig adrenals by the method of Geffen et al. (1969). The results of a typical experiment in which the eluate from the cellulose was analyzed for chromogranine are given in Fig. 1.

Several elution peaks appeared, besides the major one. Rabbits were immunized with the three fractions that gave the highest peaks. Immunodiffusion was performed on the Ouchterlony plates for demonstrating the successful immunization of the rabbits. Several precipitin lines were observed between the purified chromogranine and the rabbit serum that had been obtained (Fig. 2). Immunodiffusion was likewise performed by Ouchterlony's method on the resected tissue extract of pheochromocytoma in order to examine whether the chromogranine from the human adrenal medulla is common in antigenicity with that from the pig adrenal medulla. It was demonstrated as given in Fig. 2 that the two chromogranines are common in antigenicity.

A chromogranine assay system was devised by the use of the so obtained antiserum. The result of passive hemagglutination reaction by adding the chromograninesensitized red blood cells to a dilution series of anti-chromogranine antiserum is

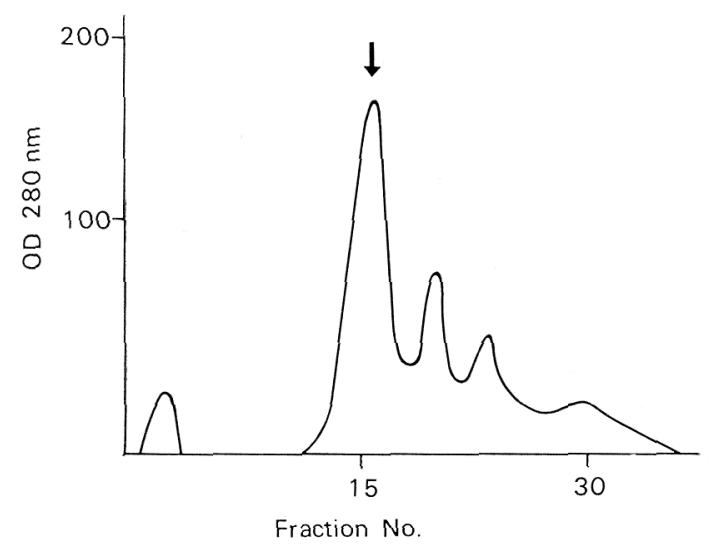

Fig. 1. Chromatogram of soluble lysate on DEAEcellulose. The soluble lysate of the vesicle was chromatographed on DEAE-cellulose equilibrated with $0.01 \mathrm{M}$ phosphate buffer $\mathrm{pH} 7.4$ at $4^{\circ} \mathrm{C}$. $\mathrm{NaCl}$-gradients $(0-0.8 \mathrm{M})$ in $0.01 \mathrm{M}$ phosphate buffer $\mathrm{pH} 7.4$ were used to elute the protein. The fractions (each containing $2.5 \mathrm{ml}$ of eluate) were collected into tubes 1-40. The optic densities of these eluates were determined at a wavelength of $280 \mathrm{~nm}$.

(The arrow shows the location of purified chromogranine)

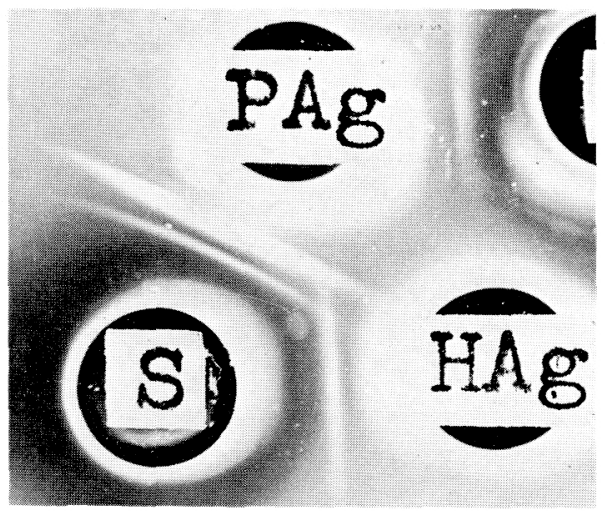

Fig. 2. Double immunodiffusion in 1\% of agar gel showing precipitin lines of identity between the purified chromogranine obtained from pig adrenal medulla (PAg), the resected tissue extract of pheochromocytoma (HAg) and the antiserum against purified chromogranine obtained pig adrenal medulla (S).

This photograph is a result of reaction at room temperature for $18 \mathrm{hr}$. In the case of the $\mathrm{HAg}$ $\mathrm{S}$ system, a single precipitin line is observed, and in the PAg-S system, a major line partially identified as the line of HAg-S system and a faint line are observed. 
Table 1. Results of passive hemagglutination reaction using sheep red cells sensitized with chromogranine and anti-chromogranine antiserum.

\begin{tabular}{cccccccc}
\hline \multicolumn{8}{c}{ dilution of antiserum } \\
\hline $1: 200$ & $1: 400$ & $1: 800$ & $1: 1600$ & $1: 3200$ & $1: 6400$ & $1: 12800$ & $1: 25600$ \\
\hline++ & + & + & + & \pm & - & - & - \\
\hline
\end{tabular}

$25 \mu l$ of a chromogranine-sensitized red blood cell suspension and $25 \mu l$ of a diluted antiserum solution were pipetted into a hole of microtray ( $U$ type) and allowed to stand at room temperature for $18 \mathrm{hr}$ for agglutination reaction.

++ ; strong agglutination, + ; moderate agglutination, \pm ; partial agglutination,

- ; no agglutination.

Table 2. Results of passive hemagglutination inhibition reaction using sheep red cells sensitized with chromogranine, the resected tissue extract of pheochromocytoma and anti-chromogranine antiserum.

\begin{tabular}{cccccccccc}
\hline \multicolumn{10}{c}{ dilution of the extracted solution } \\
\hline $1: 1$ & $1: 2$ & $1: 4$ & $1: 8$ & $1: 16$ & $1: 32$ & $1: 64$ & $1: 128$ & diluent \\
\hline- & - & - & - & \pm & + & + & + & + \\
\hline
\end{tabular}

$25 \mu l$ of an antiserum dilution $(1: 800)$ was added to $25 \mu l$ of a diluted extract and allowed to stand for $30 \mathrm{~min}$ at room temperature. Then, $25 \mu \mathrm{l}$ of a sensitized red cell suspension was pipetted into the mixture, and agglutination reaction was allowed to proceed at room temperature for $18 \mathrm{hr}$.

+ ; agglutination (no inhibition), \pm ; partial agglutination (partial inhibition),

- ; no agglutination (inhibition).

given in Table 1 . The reaction was positive to the dilution number of $1: 1600$.

For the examination of cross reactivities between the pig and human chromogranines, the resected tissue extract of pheochromocytoma was prepared into two-fold dilution series: passive hemagglutination inhibition reaction was allowed to proceed by the addition of the anti-chromogranine antiserum (dilution number of $1: 800$ ) and the sensitized red blood cells. The results of the inhibitory activities of human chromogranine in the resected tissue extract of pheochromocytoma are shown in Table 2. It was observed that the inhibitory activities of human chromogranine are $1: 8$ as shown in Table 2 .

\section{Discussion}

It is commonly accepted that chromaffin granules contain ATP and specific watersoluble proteins at high concentrations, be- sides the catecholamines. All the protein components of the granule lysate were termed "chromogranines" by Blaschko et al. (1967). However, in view of recent reports (Geffen et al., 1969; Helle, 1970), it seems advisable to restrict the term "chromogranines" to the major lysate protein component characterized by its unique amino acid composition. The term "chromogranine" was suggested by Helle (1970) as a common name for this major lysate protein component.

It is also known that chromogranine as well as the catecholamines is released by exocytosis upon stimulating the adrenal medulla. Therefore, the measurement of the catecholamines is the means of the first choice for observing the release of catecholamine-storing granules by the adrenal medulla, but the measurement of chromogranine is also a means of significance.

Chromogranine was purified by the method of Geffen et al. (1969). Rabbits 
were injected with the fraction that had given a peak level of chromogranine in DEAE cellulose chromatography, as is given in Fig. 2, as the purified chromogranine, to obtain the antiserum.

According to Geffen et al. (1969), the first peak, as indicated by its red color and its high absorbance at $410 \mathrm{~nm}$, consists chiefly of hemoglobulins. Also according to the same authors, there is a small protein peak before the highest peak, which gives high dopamine- $\beta$-hydroxylase activity. However, this small peak was not observed in our elution pattern. It may be considered that this fraction with high dopamine- $\beta$-hydroxylase activity was incorporated in the fore part of the highest peak in our elution pattern. For this reason, we collected as chromogranine the three fractions which gave the highest peaks but from which, according to Geffen et al. (1969), dopamine- $\beta$-hydroxylase activity is almost absent.

Immunodiffusion was performed by Ouchterlony's method on chromogranine as well as on the antiserum obtained by giving injection to rabbits with this chromogranine fraction, and several precipitin lines were obtained. One very large line demonstrated the successful formation of the antiserum to chromogranine. The several, very faint lines may be the subunits (molecular weight of 40,600; Kirshner and Kirshner, 1969) of chromogranine or may have been formed against the other cell fractions; however, it remains obscure what they stand for.

An assay of chromogranine was devised by means of passive hemagglutination reaction using this antiserum. No attempts have hitherto been made to determine chromogranine in man. We were the first to make the successful determination of it by means of passive hemagglutination reaction.

In conclusion, the antibodies to the chromogranine stored in the catecholaminestoring granules of the pig adrenal medulla were, as described above, successfully produced, and moreover, the so obtained antibodies were shown to have a common antigenicity with the resected tissue extract of pheochromocytoma. A chromogranine assay system was devised by the passive hemagglutination reaction system using this antiserum, and it was demonstrated on a tissue extract of pheochromocytoma that the chromogranine concentration in it could be determined as an inhibition titer. We are going to apply this method to many clinical cases of pheochromocytoma in the near future.

\section{References}

Banks, P. (1966). Biochem. J. 101, 536.

Banks, P. and K. N. Helle (1965). ibid. 97, 40.

Blaschko, H., R. S. Comline, F. Schneider, M. Silver and A. D. Smith (1967). Nature (Lond.) 215, 58.

Cambell, D. H., J. S. Garvey, N. E. Cremer and D. H. Sussdorf. Method in Immunology, W. A. Benjamin Inc., New York, p. 161 (1963).

Cox, C. D. and S. D. Vermillion (1956). J. Lab. Clin. Med. 48, 298.

Douglas, W. W. and A. M. Poisner (1966). J. Physiol. 183, 236.

Douglas, W. W., A. M. Poisner and R. P. Rubin (1965). ibid. 179, 130.

Geffen, L. B., B. G. Livett and R. A. Rush (1969). ibid. 204, 593.

Helle, K. B. (1966). Med. Pharmacol. 2, 298.

Helle, K. B. New Aspects of Storage and Release Mechanism of Catecholamines (edited by $\mathbf{H}$. J. Schumann and G. Kronenberg) Springer-Verlag, New York, p. 45 (1970).

Kirshner, A. G. and K. Kirshner (1969). Biochim. Biophys. Acta 181, 219.

Lund, A. (1950). Acta Pharmacol. 6, 137.

Munoz, J. J. Methods in Immunology and Immunochemistry, Vol. II (edited by L. A. Williams and M. W. Chase) Academic Press, New York, p. 146 (1971).

De Robertis, E. D. P. and A. Vas Ferreira (1957). Expl. Cell. Res. 12, 568.

Schneider, F. H., A. D. Smith and H. Winkler (1967). Br. J. Pharmac. Chemother. 31, 91.

Trifaro, J. M., A. M. Poisner and W. W. Douglas (1967). Biochem. Pharmac. 16, 2095. 